\title{
Analyst
}

CORRECTION

View Article Online

View Journal I View Issue

\section{Correction: A comparative study of graphene- hydrogel hybrid bionanocomposites for biosensing}

Cite this: Analyst, 2015, 140, 2044

S. L. Burrs, ${ }^{a}$ D. C. Vanegas, ${ }^{a}, \mathrm{~b}$ Y. Rong, ${ }^{a}$ M. Bhargava, ${ }^{a}$ N. Mechulan, ${ }^{a}$ P. Hendershot, ${ }^{c}$ H. Yamaguchi, ${ }^{c}$ C. Gomes ${ }^{d}$ and E. S. McLamore ${ }^{\star a}$

DOI: $10.1039 / c 5 a n 90016 f$

Correction for 'A comparative study of graphene-hydrogel hybrid bionanocomposites for biosensing' by

www.rsc.org/analyst

S. L. Burrs et al., Analyst, 2015, DOI: 10.1039/c4an01788a.

The authors regret the omission of one of the authors, Yue Rong, from the original manuscript. The corrected list of authors and affiliations for this paper is as shown above.

The Royal Society of Chemistry apologises for these errors and any consequent inconvenience to authors and readers.

\footnotetext{
${ }^{a}$ Agricultural \& Biological Engineering Department, University of Florida, 1741 Museum Road, Gainesville, FL, USA. E-mail: emclamor@ufl.edu; Tel: +1 3523921864

${ }^{b}$ Department of Food Engineering, Universidad del Valle, Ciudad Universitaria Meléndez, Edif. 338, Cali, Colombia

${ }^{c}$ Department of Mechanical and Aerospace Engineering, University of Florida, 226 MAE-B Building, Gainesville, FL, USA

${ }^{d}$ Department of Biological \& Agricultural Engineering, Texas A\&M University, 201 Scoates Hall College Station, TX, USA
} 